\title{
Caries among 3-year-olds in Greater Manchester
}

\author{
G. M. Davies, ' F. A. Blinkhorn, ${ }^{2}$ and J. T. Duxbury, ${ }^{3}$
}

\begin{abstract}
Objective To measure the prevalence of caries, including nursing caries, amongst 3-year-old children in three districts of Greater Manchester in the North West of England.

Design A cross-sectional survey of 762 randomly selected 3-yearold children using the $\mathrm{dmft}$ and $\mathrm{dmf}$ indices. Three definitions of nursing caries were used in order to assess the varying prevalence of the disease according to which definition was applied.

Subjects Children, aged 36-48 months, attending day nurseries, playgroups and nurseries attached to primary schools were examined by three trained examiners under standardised conditions in three health districts in Greater Manchester. A random selection process was used to produce a quota sample to reflect the balance of childcare provision in each district.

Results The overall proportion of children affected by general caries was $32 \%$. The mean $\mathrm{dmft}$ score was $1.4(\mathrm{sd}=2.8)$ and the mean $\mathrm{dmfs}$ was $2.8(\mathrm{sd}=7.3)$. There were significant differences across the three districts. The prevalence of nursing caries varied widely when differing definitions of types were applied; $1.6 \%$ of the children had nursing caries according to the narrow definition, $7.2 \%$ showed the wider definition type and $9.8 \%$ had nursing caries of the broadest definition. In total $19 \%$ of children had caries which affected their upper incisors. Children of Asian origin had the highest levels of nursing and overall caries.

Conclusions Caries is a widespread problem in some very young children in the districts involved. Caries of upper anterior teeth contributes significantly to the overall level of caries in each of the localities in question. The prevalence of nursing caries is highly dependent on the case definition used.
\end{abstract}

$\mathrm{T}$ here has been increased interest worldwide in the topic of nursing caries as dental epidemiologists focus on groups who are at high risk. Research symposia ${ }^{1,2}$ have highlighted the problem and the devastating effects it can have on very young children. The high prevalence among the more excluded sectors of the population has been shown in work carried out at specialist centres which aim to give additional help to such families. ${ }^{3,4}$ Clinicians will have an interest in identifying young children who have nursing caries as they may well be the patients with high levels of clinical need in the future.

A variety of criteria have been used to define nursing caries. Some authors limit the definition to caries affecting only the labial surfaces

$1^{*}$ Senior Dental Officer, ${ }^{3}$ Director of Dental Services, Mancunian Community Health NHS Trust; ${ }^{2}$ Clinical Director of Community Dental Services, Salford Community Healthcare Trust

${ }^{*}$ Correspondence to: Dr G M Davies (formerly Hawley), Senior Dental Officer (Epidemiology, Information and Research), Dental Services, Mancunian Trust, Mauldeth House, Mauldeth Road West, Manchester M21 7RL

email: Gill@daviesg28.fsnet.co.uk

REFEREED PAPER

Received 16.08.99; Accepted 03.08.00

(C) British Dental Journal 2001; 190: 381-384 of upper primary anteriors ${ }^{5,6}$ whereas others require an associated history of unfavourable feeding practices as well as evidence of caries. ${ }^{7}$ Others diagnosed nursing caries if there were carious lesions on any surface of the upper anterior teeth ${ }^{8}$ and some scoring systems required a minimum number of anterior teeth to be affected to regard cases as nursing caries. ${ }^{4,9}$ Milnes commented that 'a universally accepted definition of nursing caries does not exist' and that 'application of different classification schemata for nursing caries to the same population yields different ... prevalence rates. ${ }^{\prime}$

Studies in the UK have shown the prevalence of nursing caries ranges from 1 to $12 \%$. However, the most recent study took place over 10 years ago and others have been limited to attendees at clinics in particular localities, ${ }^{11}$ or were random samples from limited areas. ${ }^{6}$ Only one study has occurred in multiple locations and this involved health visitors assessing nursing caries by comparing the appearance of 1-2-year-old's teeth with a series of photographs. ${ }^{14}$ Most other studies have limited the definition of nursing caries to buccal or palatal surfaces of upper anteriors only. ${ }^{6,11,14}$

It is now well recognised that the prevalence of nursing caries is closely associated with infant feeding practices, ${ }^{10}$ and is influenced by cultural and socio-economic factors. ${ }^{11,14}$ For this reason it is impossible to assume a particular prevalence in one population group based on the prevalence found in another. Thus each locality would need to measure the level of nursing caries within its own population.

High levels of caries are a characteristic of the children living in the districts involved in the present study. These far exceed the dental health targets for 5-year-olds set by the Department of Health. It was considered that the prevalence of nursing caries may also be high in these districts and could contribute significantly to the caries found among 5-year-olds. As targets have been set by the Department of Health to reduce disease levels in this age group it was important to determine the nature of disease in younger age groups. For this and the reasons detailed above it was thought timely to measure the levels of caries among pre-school children in these districts. The aims of this study were to determine the prevalence and severity of caries in 3-year-old children, to measure the prevalence of nursing caries according to three different definitions and to assess associated risk factors.

\section{Fig. I Criteria for three types of nursing caries}

A child will be regarded as having nursing caries if:

Type I One or more upper primary incisors has a buccal or palatal surface affected by caries (with or without upper first molars being affected)

Type 2 One or more upper primary incisors has any surface affected by caries (with or without upper first molars being affected)

Type 3 One or more upper primary incisors has any surface affected by caries (with or without any other teeth being affected) 


\section{Method}

Three districts in Greater Manchester collaborated in this study of 3 -year-old children. In all districts there was wide state provision of childcare facilities for this age group. Approximately $90 \%$ of all children attend social services nurseries, playgroups or nurseries attached to primary schools. Very few residents attend private nurseries. A quota sampling technique was used within each district to reflect the differing child care provision. In district $\mathrm{C}$ there were more social services day nurseries, so proportionately more of these were randomly selected than in district $S$ where there was greater nursery provision at schools. A minimum of 250 children were examined in each district. Parents were advised of the planned examination.

Three experienced examiners trained together and agreed criteria, similar to those used by BASCD. ${ }^{15}$ It was considered impractical to calibrate on such young children so extensive discussion and resolution of potential areas of conflict took place. In order to maximise co-operation the children were examined visually while standing in front of the examiner who was seated or kneeling. A Daray lamp and mouth mirror aided diagnosis of caries into dentine. Soft tissues were checked for sinuses and the examiners used their judgement as to the reasons for missing incisors; where several were lost or other teeth had evidence of caries experience it was assumed that caries had been the cause.

The prevalence of nursing caries varies widely depending on the definition used ${ }^{12}$ and for this reason three types of nursing caries were defined (Fig 1). All types denote patterns of carious attack on the upper incisors but make different allowances for carious involvement of the canines and molars. They form a hierarchical scale and were applied exclusively. The criteria were as follows: Type 1 uses the most strict criteria and states that nursing caries was only diagnosed when the buccal or palatal surfaces of primary incisors were affected but allowed for upper first primary molars also being involved. ${ }^{5,6}$ Type 2 denoted nursing caries as carious involvement of any surface of the primary incisors and also allowed for upper first molars being cariously involved. ${ }^{8}$ Type 3 had the broadest definition and allowed for caries anywhere on the upper incisors with or without involvement of any other teeth. Children with evidence of anterior caries were categorised into the narrowest type according to the pattern of carious attack. The examiners applied the classification at the time of the examination. The type of child-care facility, gender and racial group were also recorded.

The data were analysed using Survey Plus version 4.0 and comparison between groups was made using $t$-tests, ANOVA and Chisquare tests. The alpha level was set at 0.05 .

\section{Results}

The population sampling frame included 7,735 children representing $91 \%$ of 3 -year-old children in the participating districts. In total, 762 children were examined; 280 in district S, 236 in C and 241 in N. Consent was withheld in only three cases. The mean age was 43 months with a range of 36 to 49 months (Table 1).

Overall, $32 \%$ of the sampled children had caries experience (Table 2). The prevalence varied significantly between the districts, with $20 \%$ of children having caries experience in district S, 31\% in C and $47 \%$ in N. The severity varied similarly; the mean $\mathrm{dmft}$ and $\mathrm{dmfs}$ in district $\mathrm{S}$ were $0.82(\mathrm{sd}=2.13)$ and $1.64(\mathrm{sd}=5.19)$, in district C $1.36(\mathrm{sd}=2.78)$ and $2.28(\mathrm{sd}=6.43)$ and in district $\mathrm{N} 2.20$ $(\mathrm{sd}=3.41)$ and $4.51(\mathrm{sd}=9.53)$. Post-hoc comparisons using a Bonferoni correction showed that the mean $\mathrm{dmft}$ and $\mathrm{dmfs}$ were significantly higher in district $\mathrm{N}$ than in the other two districts. Overall the mean $\mathrm{dmft}$ was $1.4(\mathrm{sd}=2.8)$ and the $\mathrm{dmfs} 2.8(\mathrm{sd}=7.3)$.

Among those children with caries experience there were no significant differences in mean severity scores (Table 2 ) suggesting that the differences in overall mean scores occurred as a result of the differences in the proportion of caries free children. It would seem that children in District $\mathrm{N}$ did not have more extensive caries than those in other districts but that a higher proportion of children were affected.

The prevalence of nursing caries appeared to increase for the broader criteria types (Table 3). Among the sample overall, $1.6 \%$

Table I Details of the sampled children

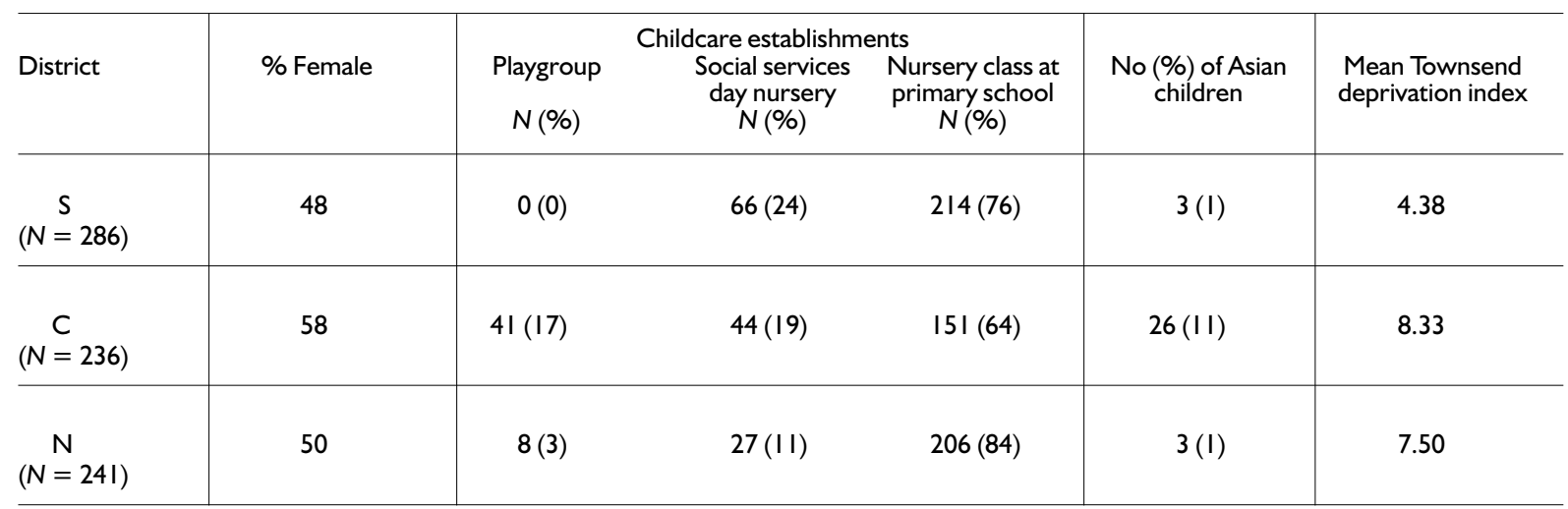

Table 2 General caries prevalence and severity among 3-year-old children in three districts in Greater Manchester. (Total sample and those with caries experience)

\begin{tabular}{|c|c|c|c|c|c|c|}
\hline \multirow[t]{2}{*}{ District } & \multirow[t]{2}{*}{ Number examined } & \multicolumn{2}{|c|}{ Total sample } & \multicolumn{3}{|c|}{ Children with caries experience $(\mathrm{dmft}>0)$} \\
\hline & & Mean dmft (sd) & Mean dmfs (sd) & $N(\%)$ & Mean dmft (sd) & Mean dmfs (sd) \\
\hline $\mathrm{S}$ & 280 & $0.82(2.13)$ & $1.64(5.19)$ & $56(20)$ & $4.09(3.05)$ & $8.20(9.06)$ \\
\hline $\mathrm{C}$ & 236 & $1.36(2.78)$ & $2.28(6.43)$ & $74(3 I)$ & $4.35(3.43)$ & $7.27(9.82)$ \\
\hline $\mathrm{N}$ & 241 & $2.20(3.4 I)$ & $4.51(9.53)$ & $115(47)$ & $4.71(3.6 I)$ & $9.64(12.06)$ \\
\hline Total & 762 & $1.43(2.85)$ & $2.76(7.31)$ & $244(32)$ & $4.46(3.43)$ & $8.60(10.79)$ \\
\hline ANOVA & & $P<0.001$ & $P<0.001$ & $P<0.001$ & $P=0.51$ & $P=0.32$ \\
\hline
\end{tabular}


Table 3 Prevalence of nursing caries in three districts using three definitions

\begin{tabular}{l|c|cccc}
\hline & & \multicolumn{4}{|c}{ Number with nursing caries (\%) } \\
District & $N$ & Type I & Type 2 & Type 3 & Any type \\
\hline $\mathrm{S}$ & 280 & $6(2.1)$ & $15(5.4)$ & $12(4.3)$ & $33(1 \mathrm{I} .8)$ \\
$\mathrm{C}$ & 236 & $9(0.4)$ & $17(7.2)$ & $16(6.8)$ & $34(14.4)$ \\
$\mathrm{N}$ & 246 & $5(2.0)$ & $23(9.3)$ & $47(19.1)$ & $75(30.5)$ \\
\hline Total & 762 & $12(1.6)$ & $55(7.2)$ & $75(9.8)$ & $142(18.6)$ \\
\hline Chi-square & & & & $P<0.01$ & $P<0.0 \mathrm{I}$
\end{tabular}

Table 4 Comparison of prevalence of nursing and general caries and severity between 3-year-olds of Asian and non-Asian racial background in district $\mathrm{C}$

\begin{tabular}{|c|c|c|c|c|c|c|c|}
\hline & \multirow[b]{2}{*}{$N$} & \multicolumn{2}{|c|}{ General caries } & \multicolumn{4}{|c|}{ Number with nursing caries (\%) } \\
\hline & & $\begin{array}{c}\text { Mean } \\
\operatorname{dmft}(S D)\end{array}$ & $\begin{array}{c}\text { Number with caries } \\
\text { experience }(\%)\end{array}$ & Type I & Type 2 & Type 3 & Any type \\
\hline Asian & 26 & $2.58(3.70)$ & $10(38)$ & I (3.8) & $3(I 1.5)$ & $5(19.2)$ & $9(35)$ \\
\hline Non-Asian & 210 & $1.21(2.62)$ & $42(20)$ & $0(0)$ & $14(6.7)$ & II (5.2) & $25(11.9)$ \\
\hline
\end{tabular}

had Type 1 nursing caries. The prevalence of children with nursing caries fulfilling the requirements of Type 2 was larger with $7.2 \%$ affected overall. The largest prevalence was seen for children who had Type 3 nursing caries with $9.8 \%$ so affected. If all three nursing caries patterns are considered together, $19 \%$ of children were found to be affected.

The prevalence of nursing caries increased within each district as wider definitions were applied but this increase was not uniform; in district $\mathrm{S}$, where the prevalence was lowest, the increase in affected children was small with $2 \%$ of children having nursing caries which fulfilled criteria of Type 1, 5\% with Type 2 and $4.3 \%$ with Type 3. Twelve per cent of all sampled children in $S$ had caries which affected their upper incisors. In district $\mathrm{C}$ less than $1 \%$ of children had nursing caries of the Type 1 pattern, 7.2\% had Type 2 and $6.8 \%$ had Type 3. Adding together all three types resulted in a prevalence of nursing caries of $14 \%$. The highest prevalence levels were recorded in district $\mathrm{N}$ where nursing caries patterns of the three types were found among $2 \%, 9.3 \%$ and $19 \%$ of the sample respectively. In this district $30 \%$ of children had one or more carious or missing incisors. Statistically significant differences in prevalence were found between district $\mathrm{N}$ and the other districts with regard to Type 3 nursing caries and when all types were added together and compared.

No statistically significant differences were found between boys and girls or between children attending differing types of child care provision. However, in district $C$ there were sufficient Asian children to compare with other racial groups and the severity of general caries and the prevalence of nursing caries was found to be higher among Asian children than among their non-Asian peers (Table 4). The mean $\mathrm{dmft}$ among Asian children (2.58) was more than twice that of non-Asian children (1.21). Thirty eight per cent of Asian children had caries experience compared with $20 \%$ of non-Asian children.

The prevalence of all types of nursing caries was higher among Asian children with $3.8 \%$ affected by Type $1,11.5 \%$ affected by Type 2 and $19 \%$ by Type 3 (Table 4). In contrast, no non-Asian children in district $C$ had Type 1 pattern nursing caries, $6.7 \%$ had Type 2 and $5.2 \%$ Type 3 . The overall prevalence of nursing caries was significantly higher among Asian children; $35 \%$ of sampled children had nursing caries of some type compared with only $12 \%$ of non-Asian children.

\section{Discussion}

Relatively few problems were encountered in accessing children of this age group in Greater Manchester as so many attend some form of childcare centre. Some possible bias should be considered as the children who were cared for at home or with childminders were inaccessible and their dental health may have been different from those attending child care centres. All three examiners felt comfortable applying the criteria for diagnosis and the description of nursing caries by one of three types proved straightforward.

The high levels of general and nursing caries are of concern. In districts $\mathrm{C}$ and $\mathrm{N}$ the severity and prevalence among these 3 -year-olds already exceed the national target figures for 5 -year-olds set by the Department of Health. ${ }^{17}$ These include the aim of a mean dmft of 1 for 5-year-olds by the year 2003 and a prevalence of caries experience of $30 \%$. Even in district S, where severity and prevalence are lower, it is unlikely that caries development between the ages of three and five will be low enough to keep within the target.

The effect of differing classifications of cases of nursing caries on prevalence is clear. Type 1 regards carious involvement of the buccal and palatal surfaces of upper incisors, with or without caries on the upper first molars, as being a case of nursing caries. This excludes all children who have caries on other surfaces of the incisors and those who may have developed caries on canines or second molars after the onset of nursing caries. Thus, in studies using this definition many cases of anterior caries are excluded. The wider definition, Type 2, accepts that nursing caries can affect any surface of the upper incisors and would appear to be more realistic in its measurement. It also includes extracted upper incisors, about which nothing is known regarding the pattern of carious attack, only that it was severe enough to warrant extraction. However it excludes children who develop general caries on second molars and canines which occurred after the period when nursing caries was most likely.

The third type, which allows for caries on the upper incisors with or without caries on any other teeth, is more suitable for older children whose primary dentition is complete. It counts all cases of nursing caries whether or not general caries has occurred later on. This last definition seems to be the most appropriate in areas where nursing caries and general caries levels are high. It makes little sense 
to exclude all those cases of nursing caries simply because general caries is evident later.

Most epidemiological measurements have to achieve a compromise between accurate measurement, assumptions about aetiology and limited access to background information. In this study no data could be collected with regard to weaning and drinking habits, past or present, for the sampled children. However many previous studies have shown the associations between nursing caries and delayed weaning, long-term bottle use with cariogenic drinks and various psychosocial factors. ${ }^{11}$

It is possible that the local cultures surrounding weaning and child rearing could explain the variations between districts with regard to nursing caries. In district $S$ it may be less acceptable for children to be given a bottle to take to bed and parents may be more aware of safe baby drinks. In contrast, parents in district $\mathrm{N}$ may prefer to delay their baby's progression onto a feeder cup and be less aware of the cariogenic effects of many baby drinks. It has been shown that Asian parents are more likely to keep their children on bottles of milk sweetened with sugar, rusks or honey ${ }^{16}$ for years and this could be why the level of nursing caries is higher among Asian children in district C. Local social support for healthy or more harmful child-rearing practices is likely to be an important influence on the prevalence of nursing and general caries.

\section{Conclusions}

General and nursing caries is still a significant problem among very young children in some areas and in particular racial groups in Greater Manchester. Regardless of the definition of cases of nursing caries it is unlikely that Department of Health targets for 5-yearolds ${ }^{17}$ will be met if the problem of caries occurring in very early childhood is not addressed in these areas.

The measurement of nursing caries prevalence varies widely depending upon the definition of the pattern of attack that is used. The age of the sample and the prevalence of general caries need to be taken into account when an appropriate definition is being selected.
The authors are grateful for the willing co-operation of the staff, children and parents at the child-care centres involved.

1 Billings R J et al. Symposium: needed - a research agenda for nursing caries. J Public Health Dent 1996; 56: 37-60.

2 Tinanoff $\mathrm{N}$ et al.Early childhood caries conference. Community Dent Oral Epidemiol 1998; 26: Supplement 1; 5-7.

3 Weinstein P, Domoto P, Wohlers K, Koday M. Mexican-American parents with children at risk for baby bottle tooth decay: pilot study at a migrant farm workers' clinic. J Dent Child 1992; 59 : 376-383.

4 Barnes G P, Parker W A, Lyon Jr T C, Drum M A, Coleman G C. Ethnicity, location, age and fluoridation factors in baby bottle tooth decay and caries prevalence of Head Start children. Public Health Reports 1992; 107: 167-173.

5 Richardson B D, Cleaton-Jones P, McInnes P, Rantsho J. Infant feeding practices and nursing bottle caries. J Dent Child 1981; 48: 289-393.

6 Silver D H. A comparison of 3-year-olds caries experience in 1973, 1981 and 1989 in a Hertfordshire town, related to family behaviour and social class. Br Dent J 1992; 172: 191-197.

7 Powell D. Milk: is it related to rampant caries of the early primary dentition? J Can Dent Assoc 1976; 4: 58-63.

8 Serwint J R, Mungo R, Negrete V F, Duggan A K, Korsch B M. Child rearing practices and nursing caries. Pediatrics 1993; 92: 233-237.

9 Paunio P, Rautava P, Helnius H, Alanen P, Sillanpaa M. The Finnish Family Competence Study : the relationship between caries dental health habits and general health in 3-year-old Finnish children. Caries Res 1993; 27: 154160.

10 Seow W K. Biological mechanisms of early childhood caries. Community Dent Oral Epidemiol 1998; 26: Supplement 1: 8-27

11 Reisine S, Douglass J M. Psychosocial and behavioural issues in early childhood caries. Community Dent Oral Epidemiol 1998; 26: Supplement 1: 32-44

12 Milnes A R. Description and Epidemiology of Nursing Caries. J Public Health Dent 1996; 56: 38-50.

13 Holt R D, Joels D, Bulman J, Maddick I H. A third study of caries in preschool aged children in Camden. Br Dent J 1988; 165 : 87-91.

14 Goose D H, Gittus E. Infant feeding methods and dental caries. Public Health 1968; 83: 72-76.

15 Pitts N B, Evans D J, Pine C M. British Association for the Study of Community Dentistry (BASCD) diagnostic criteria for caries prevalence surveys - 1996/97. Comm Dent Health 1997; 14 (Supplement 1): 6-9.

16 Williams S A, Sahota P, Fairpo C G. Infant feeding practices within white and Asian communities in inner-city Leeds. J Hum Nutr Dietetics 1989; 2 325-328.

17 An oral health strategy for England. Department of Health, 1994. 